\title{
PAULO FOGAÇA: ASPECTOS DE UMA POÉTICA
}

\section{Rosane Andrade de Carvalho - Bolsista Capes}

Programa de Pós-Graduação Mestrado em Cultura Visual da Faculdade de Artes Visuais - UFG.

Orientador: Prof. Dr. Luis Edegar de Oliveira Costa

Diferentes estudos sobre os anos 60 e 70 no Brasil os qualificam como um momento de efervescência político-social e artística-cultural. No quadro político e social o país vivia sob o regime militar instaurado em 1964, implantando um clima de autoritarismo, cerceamento, perseguição e violência sobre as diferentes instâncias da sociedade brasileira, fazendo surgir ações reativas a essa realidade, sobretudo nos meios artístico e cultural. No campo da estética fez-se urgente a expansão das possibilidades de expressão nas artes visuais em contraponto aos procedimentos tradicionais. E ainda, a reivindicação de um posicionamento crítico do artista, um olhar em consonância com sua realidade imediata. Trabalhos voltados para a crítica não só aos meios tradicionais de produção artística, mas, sobretudo, de denúncia da censura e violência imposta pelo poder militar davam a tônica do momento.

O crítico Paulo Sérgio Duarte (2005) identifica duas vertentes no meio artístico brasileiro que atuam no interior das relações entre arte e política nos anos 60 e 70 . Uma estaria centrada numa crítica direta ao regime militar, onde os artistas buscam responder às ações repressivas sem, no entanto, descuidar das questões de ordem estética, e uma outra estaria preocupada em problematizar o sistema geral da arte, ou seja, o seu circuito institucionalizado.

A atitude contestatória nas produções dos anos 60 é observada nos diferentes discursos dos críticos, teóricos e artistas brasileiros, especialmente nos eventos Opinião 65/66, realizados no Museu de Arte Moderna do Rio de Janeiro e Propostas 65 e 66 realizados na Fundação Armando Álvares Penteado em São Paulo. Esses eventos significaram momentos de rica produção e discussão sobre a arte brasileira no contexto do ressurgimento da figuração na arte e do momento social e político conturbado do país perante a presença do Estado Militar. O diagnóstico sobre a produção artística brasileira empreendido nesses eventos desembocou na Declaração dos Princípios Básicos da Vanguarda, publicada em janeiro de 1967 e no Esquema Geral da Nova Objetividade, este redigido por Hélio Oiticica publicado no catálogo da mostra Nova Objetividade Brasileira, 
realizada no Museu de Arte Moderna do Rio de Janeiro no mesmo ano. Dos diferentes posicionamentos expressos nos discursos de críticos e artistas como Mário Pedrosa, Frederico Morais, Mário Schenberg e Hélio Oiticica, citando somente alguns nomes, nota-se a convergência de idéias quanto a percepção da existência de uma vanguarda que se apoiava na relação com a realidade brasileira, e na tentativa de afirmação e independência dessa vanguarda frente às vertentes internacionais.

A assimilação que a arte brasileira faz das vertentes internacionais ocorre em termos antropofágicos e não como apropriação direta das características formais e ideológicas dessas vertentes. $\mathrm{Na}$ verdade, essas vertentes ganham designações próprias coerentes com o contexto histórico brasileiro, numa espécie de tradução dos propósitos e estratégias utilizadas pelas mesmas.

O sentido antropofágico oswaldiano percebidos nas produções de alguns artistas, como por exemplo, Hélio Oiticica e Lygia Clark, é defendido por Paulo Sérgio Duarte e pelo próprio Oiticica. Ambos defendem ser a antropofagia uma característica da cultura brasileira. Duarte (2005) vai mais além, afirmando que o sentido antropofágico oswaldiano somente se efetivou nos anos 60 com Lygia Clark e Hélio Oiticica, sendo que nesse último o "outro" incorporado ou deglutido, não é mais o estrangeiro ou o colonizador, mas algumas manifestações da própria cultura urbana brasileira, a exemplo de Tropicália que alude às favelas brasileiras. Oiticica em seu Esquema Geral da Nova Objetividade, publicado em 1967, também reitera a característica antropofágica da cultura brasileira, diz o artista:

A antropofagia seria a defesa que possuímos contra tal domínio exterior, e a principal arma criativa, essa vontade construtiva, o que não impediu de todo uma espécie de colonialismo cultural, que de modo objetivo queremos hoje abolir, absorvendo-o definitivamente numa superantropofagia (OITICICA, 2006, p. 155).

É a partir desse conjunto de circunstâncias que Paulo Fogaça desenvolve um tipo de produção que pode ser situada entre a contestação política e o experimentalismo estético, buscando no repertório imagético do Centro-Oeste matéria e inspiração para a sua poética.

Nascido na cidade de Morrinhos, interior de Goiás, em 1936, Paulo Fogaça passa sua infância entre a capital do Estado e sua cidade de origem. Atua como professor de engenharia na Universidade Federal de Goiás até 1964, quando da intervenção do poder militar no Brasil, mudando-se para a cidade do Rio de Janeiro em 1965. Na capital carioca, 
seu interesse pelo cinema o leva a freqüentar assiduamente a Cinemateca do Museu de Arte Moderna (MAM/RJ), local de grande movimentação artística e espaço de experimentação estética. No MAM/RJ dá-se a formação artística de Fogaça através da realização de cursos livres a partir de 1969, desenho com Aloísio Carvão, história da arte com Frederico Morais, gravura com José Assumpção de Souza, objeto com Ivan Serpa e escultura com Pedro Correia e Maurício Salgueiro. No MAM/RJ aproximase das pesquisas estéticas comprometidas com o desenvolvimento de novas linguagens, destacando a fotografia, o audiovisual e o filme super-8. Realiza uma série de trabalhos individuais ou em colaboração com outros artistas como, Frederico Morais e Anna Maria Maiolino, utilizando os novos meios. Com o primeiro realizou as fotografias dos audiovisuais: Memória da Paisagem (1970), Cantares (1971), Curriculum Vitae (1972/73) e outros. Com Maiolino colaborou na realização das fotografias de Construção (1973) apresentado na VIII Bienal de Jovens de Paris no mesmo ano, na qual Fogaça também participa com o audiovisual Bichomorto (1973).

O que diferencia o conjunto da produção de Paulo Fogaça é a sua referência imagética, que busca no seu local de origem e na sua memória de infância os elementos necessários para a concretização de suas idéias. É nesse sentido, que em toda a sua produção surgem objetos identificadores do Centro-Oeste brasileiro como, ferramentas rurais, arames farpados e a paisagem do cerrado que, agenciados às linguagens, por vezes experimentais, e a uma visão crítica de seu contexto constituem a poética do artista.

A série Hieróglifos, desenvolvida entre 1973-1977, é um exemplar da pesquisa plástica de Fogaça, pois evidencia as suas preocupações de caráter estético e de crítica social e os procedimentos técnicos tomados pelo artista. Nessa série Fogaça transita pelas diferentes técnicas e linguagens artísticas. Explora a fotografia, a serigrafia e o audiovisual, este realizado em 1973 e de título homônimo à série, faz ainda pequenas incursões pelo desenho e pela pintura.

O que predomina nessa série é a idéia, o conceito. Fogaça toma o arame farpado, ou fragmentos dele, como signo de uma situação, como referências simbólicas de uma dada realidade. Este elemento, que objetiva o afastamento e a coerção, é encontrado, sobretudo no meio rural como delimitador das áreas das propriedades, obstáculo a passagem do gado. Transposto para os audiovisuais, serigrafias, pinturas, desenhos e objetos, ganha um caráter crítico que parece aludir ao cerceamento e estado de violência impostos pela ditadura militar. As circunstâncias sociais e políticas 
do país daquele momento permitem tal associação, sendo esta observada também pelo crítico Frederico Morais em artigo publicado em 1977:

A cerca, a farpa. O detalhe ampliado, visto em primeiro plano serigráfico, surge como nó ou torção. A ponta metálica rasga fere, corta, como espinho; o nó aperta, comprime, sufoca, cala. Esta associação nó/farpa (...) é, sobretudo para o espectador "urbano", uma imagem visualmente agressiva e violenta (1977 apud FIGUEIREDO, 1979, P. 124).

A descrição feita por Morais é bastante evidente na série de imagens que compõem o audiovisual Hieróglifos (1973). O artista destaca o arame farpado em seus aspectos intrínsecos. Ora, sobrepõe esse objeto à artigos jornalísticos da época, ora interfere diretamente sobre ele com manchas gráficas, ou ainda, intercala essas imagens com desenhos de manuais de anatomia humana. $\mathrm{O}$ corpo ali expresso é o mesmo que serve como suporte para a tortura, para o aprisionamento.

A farpa surge também em placas de trânsito (fig.1), cartas, partituras, sinais geométricos, histórias em quadrinhos associada a um tipo de escritura; uma escritura a ser decifrada, como assim sugere o título da série. Uma mensagem que, estaria relacionada ao tempo e espaço vivido pelo artista, não só como momento presente, mas como memória de um passado que ficou retido e que agora se articula com o momento atual criando novas significações, mas como que veladas, por um código que a censura não traduziria. Metáfora ou mensagem política de uma época, essa série evidencia a posição crítica de Fogaça requerida pelo momento político e de renovação da sensibilidade.

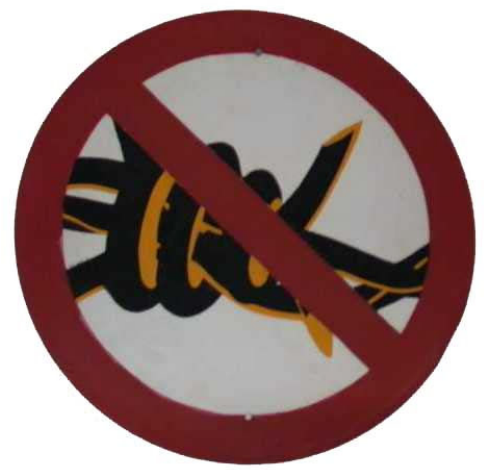

Figura 1. Sem título. Da série Hieróglifos. 1976/1977

Placa de sinalização e tinta $50 \mathrm{~cm}$ de diâmetro 
Nesta série de trabalhos pode-se entrever ainda um diálogo com as linguagens dos mass-media, como as técnicas de apropriação e reprodução, emprego de placas de sinalização, carimbos e história em quadrinhos. Uma característica presente em trabalhos de outros artistas como Rubens Gerchman e Carlos Vergara, por exemplo, como um tipo de aproximação ou tradução das vertentes internacionais de caráter neofigurativo ${ }^{1}$ que aportaram no país em meados dos anos 60.

A década de 1970 mostra-se significativa no que se refere às experiências com os novos meios. Os audiovisuais e filmes super-8 serviram a diferentes artistas como meios expressivos. Estes trabalhos apresentaram-se também como forma de resistência à censura do regime militar vigente. Em Expoprojeção 73, mostra coletiva de trabalhos de artistas brasileiros em audiovisual, filmes super- 8 e $16 \mathrm{~mm}$ e pesquisas com som, realizada em São Paulo e organizada pela crítica Aracy Amaral, Fogaça apresenta os audiovisuais Ferrofogo (1972) e Bichomorto (1973).

Ferrofogo é um trabalho que, segundo o artista, propõe discutir o audiovisual como linguagem e meio de expressão. Fogaça constrói imagens distorcidas pela simples manipulação de objetos - tubos de ensaios e elementos orgânicos - registrados pela lente da câmera fotográfica, numa atitude que busca explorar as possibilidades experimentais desse meio. Em Bichomorto as imagens são captadas durante uma viagem do artista do Rio de Janeiro à cidade de Goiânia. São animais dilacerados pelos carros nas rodovias, nesses espaços de ligação entre dois universos - o rural e urbano. A paisagem por vezes é limpa, fria e solitária. Noutros momentos são os carros com seu movimento incessante que surgem, ora na estrada, ora na cidade, quebrando o ritmo melancólico da paisagem. O animal que jaz nas estradas parece indiciar um estado, uma condição de existência da vida humana naquele momento, uma declaração da banalização da vida pela violência.

Em Cabeça-Tronco-Membros, audiovisual produzido ainda em 1973, Fogaça também conjuga a crítica social ao experimentalismo da linguagem. Com este trabalho integra a XII Bienal de São Paulo realizada no mesmo ano. Em entrevista Fogaça descreve esse trabalho:

1 As tendências neofigurativas referenciadas aqui são o Novo Realismo Francês e a Pop-art norteamericana que tiveram repercusões sobre a produção brasileira através, especialmente das mostras Outra figuración (Galeria Bonino, RJ/1963) e Nouvelle Figuration (Galeria Relevo, RJ/ 1964) organizadas por Ceres Franco e Jean Bojhici. 
Cabeça-Tronco-Membros, tendo a mesma motivação de Hieróglifos, foi uma experiência de um desenho animado usando a rápida passagem de um slide a outro, com um bonequinho recortado em cartolina que fazia continências até cair como um monte de partes (cabeça, tronco e membros) ao som da Marcha Militar de Schubert. ${ }^{2}$

Trabalhando ainda com elementos extraídos do universo rural concebe trabalhos tridimensionais pela apropriação e justaposição de ferramentas como, enxadas, enxós, picaretas e foices (fig.2). Esses trabalhos, realizados entre 1976 e 77 no Estado de Goiás, é um desdobramento de sua pesquisa iniciada ainda em 1969 quando da realização de Rosas dos Caminhos, uma espécie de rosácea construída a partir de oito enxadões de ferro, que integrou o I Salão da Bússola, realizado no Museu de Arte Moderna do Rio de Janeiro em novembro do mesmo ano.

Objetos construídos a partir da apropriação de outros objetos de uso cotidiano retomam os procedimentos dadaístas e especialmente o gesto radical de Marcel Duchamp. A apropriação opera diretamente na função original do objeto, empreende a descaracterização do mesmo a fim de resignificá-lo. Segundo Benjamin Buchloh (2000), é um procedimento de caráter alegórico, e que, portanto permite dizer algo, mesmo que implicitamente, que não poderia ser dito livremente.

Fogaça intitula esses trabalhos de Totens, propondo-os como objetos reveladores de uma situação de violência e medo vivenciada por uma determinada sociedade (no caso a brasileira). Lida com as questões de tempo, atribuindo sentido arqueológico a esses trabalhos, o que fica ainda mais evidente em Fóssil, trabalho de 1976, no qual uma enxada é incrustada sobre um bloco de pedra, à semelhança de um bloco monolítico histórico, uma espécie de evidência material. Ou ainda, em A Pedra (1976), onde Fogaça imprime as marcas do arame farpado sobre um bloco de pedra, referenciando as inscrições da famosa Pedra de Roseta.

\footnotetext{
${ }^{2}$ Entrevista concedida pelo artista em 29 de agosto de 2005, na cidade de Goiânia, Goiás.
} 


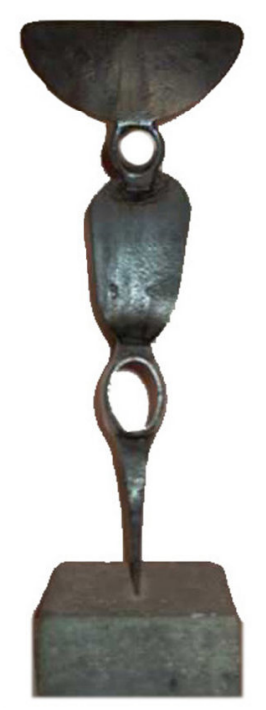

Figura 2 - Totem 2-62-22, 1976/77.

Enxada, picareta, pedra reconstituída e solda $21 \times 54 \times 8 \mathrm{~cm}$

A historiadora e crítica de arte Aline Figueiredo em estudo sobre a produção artística do Centro-Oeste aponta o caráter arqueológico presente nos trabalhos de Paulo Fogaça e as contribuições dessa produção para a arte brasileira e goiana. Comenta:

Transpira em tudo, um sentido arqueológico. Uma linguagem/símbolo para ser decifrada no futuro, enigma de um universo rural. Também as enxadas e as foices, retiradas do uso, são apropriadas por Fogaça compondo objetos entrelaçados, testemunhos de um tempo e de uma circunstância (FIGUEIREDO,1979, p. 123).

O jogo temporal e espacial está presente também no audiovisual Campo Cerrado (1975). Nesse trabalho a paisagem do cerrado goiano é captada em todas as suas fases. As transformações da paisagem do Planalto Central, decorrentes das mudanças climáticas e da ação depredadora do homem, são evidenciadas na seqüência de 65 imagens em conjunção com texto do botânico dinamarquês Eugenio Warming de 1892 que descreve o processo de transmutação dessa paisagem. Em Campo Cerrado, como nos demais audiovisuais, Fogaça utiliza o termo diapoema como denominação e 
qualificação desses trabalhos, como que sugerindo esses diapositivos como poemas visuais.

Residindo no Estado de Goiás desde meados dos anos 1970 cria e coordena o Museu Experimental de Arte Visuais no Departamento de Artes e Arquitetura da Universidade Católica de Goiás entre 1979 e 1981. Lá organiza o I Salão Experimental (1981), onde desenvolve pesquisas nas áreas das artes visuais e do teatro e, ainda, a mostra Objeto Rural como resultado da pesquisa homônima, coordenada por Fogaça, que objetivava o levantamento e registro audiovisual de objetos típicos do homem rural de Goiás. O que se tem hoje de registro sobre a existência do Museu, bem como de suas atividades se resumem tão-somente a um catálogo da exposição fotográfica Objeto Rural e depoimentos cedidos pelo artista como o que segue:

Eu lidava com os estudantes de arquitetura que eram avançados, que topavam esses experimentalismos, (...) Aquilo era assim: as pessoas que freqüentavam o Museu, eu propus a eles que nós fizéssemos um levantamento sobre os objetos rurais, então a gente visitou fazendas (...) e fotografando e documentando os diversos tipos de objetos que eram usados naquele contexto. (...). ${ }^{3}$

Logo após o encerramento das atividades do Museu Experimental Fogaça afasta-se da produção plástica para dedicar-se ao campo teórico. $\mathrm{O}$ artista considera essa mudança como uma segunda fase na sua relação com a arte. Viaja à França em 1984, permanecendo por dois anos, período no qual realiza mestrado em Filosofia da Arte e da Cultura na Universidade de Paris, Sorbone, com o trabalho As imagens Informáticas: perguntas estéticas feitas por um novo sistema visual.

Retornando ao país faz uma rápida participação no Grupo Infoestéticat na Universidade de Brasília (UNB), de 1990 a 1993, quando Fogaça retorna à Goiânia, onde vive até os dias atuais.

O conjunto da obra de Paulo Fogaça demonstra um olhar atento aos novos meios tecnológicos de produção de imagens e de objetos artísticos e com os problemas sociais do Brasil. Transitando entre os universos rural e urbano absorve criticamente as questões sócio-culturais e

3 Entrevista cedida pelo artista em 29/07/2005 na cidade de Goiânia, Goiás.

4 O Grupo Infoestética iniciou suas atividades em 1987 na Universidade de Brasília desenvolvendo pesquisas no contexto da arte e tecnologia. Contava com professores das áreas de arte visuais e computação. Foi criado por Aluízio Arcela e Suzete Venturelli, tendo ainda como integrantes Tânia Fraga, Agnes Daldegan e Paulo Fogaça. O Grupo se dissolveu em 1994 retornando em 2001 com Aluízio Arcela, Suzete Venturelli e alunos de iniciação científica. 
artísticas existentes nos mesmos, que são materializadas em suas produções. Uma produção que responde ao que se apresentava naquela época, que consegue articular a experimentação artística com a reação à repressão militar.

\section{Bibliografia}

BUCHLOH, Benjamin. Procedimentos alegóricos: apropriação e montagem na arte montagem na arte contemporânea. Arte \& Ensaios - Revista do Programa de Pós-Graduação em Artes Visuais EBA/UFRJ, Rio de Janeiro, n.7, p. 179-197, 2000.

FIGUEIREDO, Aline. Artes Plásticas no Centro-Oeste. Cuiabá: Edições UFMT/MACP, 1979.

DUARTE, Paulo Sérgio. Anos 70: a arte além da retina. In.: RISÉRIO, Antônio et. al. Anos 70: trajetórias. São Paulo: Iluminuras; Itaú Cultural, 2005. p. 133-146.

GULLAR, Ferreira. Opinião 65. Arte em Revista, São Paulo, n.2, $2^{a}$ edição, p. 22-23, março. 1983. p. 22-23.

MORAIS, Frederico. É preciso decifrar. A esperança renasce. O Globo, Rio de Janeiro, 31-8-1977. sem paginação.

OITICICA, Hélio. Esquema geral da Nova Objetividade. In.: FERREIRA, Glória; COTRIM, Cecília (orgs). Escritos de Artistas: anos 60/70. Rio de Janeiro: Jorge Zahar Editor, 2006. p. 154-168.

RIBEIRO, Marília Andrés. Arte e Política no Brasil: a atuação das neovanguardaas nos anos 60. In: FABRIS, Annateresa (org.) Arte \& Política: algumas possibilidades de leitura. São Paulo: FAPESP; Belo Horizonte: C/Arte, 1998.

SCHENBERG, Mário. O Ponto Alto. Arte em Revista, São Paulo, n.2, $2^{\mathrm{a}}$ edição, p. 22-23, março. 1983. p. 25. 